\title{
Rutting Prediction in Asphalt Pavement Based on Viscoelastic Theory
}

\author{
Mohammed Hadi $\mathrm{Nahi}^{1{ }^{1, *}}$, Ibrahim Kamaruddin ${ }^{1}$, and Madzlan Napiah ${ }^{1}$ \\ ${ }^{1}$ Civil and Environmental Engineering Department, Universiti Teknologi Petronas, \\ Bandar Seri Iskandar 32610, Tronoh, Perak, Malaysia
}

\begin{abstract}
Rutting is one of the most disturbing failures on the asphalt roads due to the interrupting it is caused to the drivers. Predicting of asphalt pavement rutting is essential tool leads to better asphalt mixture design. This work describes a method of predicting the behaviour of various asphalt pavement mixes and linking these to an accelerated performance testing. The objective of this study is to develop a finite element model based on viscoplastic theory for simulating the laboratory testing of asphalt mixes in Hamburg Wheel Rut Tester (HWRT) for rutting. The creep parameters $\mathrm{C} 1, \mathrm{C} 2$ and $\mathrm{C} 3$ are developed from the triaxial repeated load creep test at $50^{\circ} \mathrm{C}$ and at a frequency of $1 \mathrm{~Hz}$ and the modulus of elasticity and Poisson's ratio determined at the same temperature. Viscoelastic model (creep model) is adopted using a FE simulator (ANSYS) in order to calculate the rutting for various mixes under a uniform loading pressure of $500 \mathrm{kPa}$. An eight-node with a three Degrees of Freedom (UX, UY, and UZ) Element is used for the simulation. The creep model developed for HWRT tester was verified by comparing the predicted rut depths with the measured one and by comparing the rut depth with ABAQUS result from literature. Reasonable agreement can be obtained between the predicted rut depths and the measured one. Moreover, it is found that creep model parameter $\mathrm{C} 1$ and $\mathrm{C} 3$ have a strong relationship with rutting. It was clear that the parameter $\mathrm{C} 1$ strongly influences rutting than the parameter C3. Finally, it can be concluded that creep model based on finite element method can be used as an effective tool to analyse rutting of asphalt pavements.
\end{abstract}

\section{Introduction}

Rutting is one of the wide common deformations for flexible pavement roads. For proper pavement design and better understanding of materials behaviour it is necessary to predict asphalt pavement rutting [1]. Rutting phenomenon is the longitudinal depressions along the wheel paths caused by the movement of asphalt pavement materials under high traffic loading based on consolidation or plastic flow [2,3]. Excessive amount of asphalt cement is one of reasons for plastic flow [4,5]. Rutting in asphalt pavement is mainly occurring due to its nonlinear viscoelastic nature [6,7]. The high wheel loads and high tire pressures are the main cause for Increasing of asphalt pavement rutting phenomenon [8,9]. Magdy, (1996) presents three rutting mechanisms wear rutting, structural rutting and instability rutting

\footnotetext{
* Corresponding author: mohammednahi2@gmail.com
} 
[10]. This study deals with the last type, which is the most dangerous type of surface rutting. Sue and Wong (2009) has studied the air voids effects on the behaviour of rutting under wheel loadings. An eight-node, three-dimensional stress, displacement element was used in the finite element analysis. A study in (2003) developed a finite element model to simulate the laboratory testing of asphalt mixes in Asphalt Pavement Analyzer (APA) test for rutting and to relate the test results to basic material properties, a visco-elasto-plastic model (creep model) has been used to represent the time-dependent characteristics of the asphalt mixture [11, 12]. The objective of this study is to develop a finite element model to simulate the laboratory testing of asphalt mixes in (HWRT) for rutting. The nonlinear viscoelastic behaviour analysis of asphalt mixes was adopted in this study. It was found that creep model parameters $\mathrm{C} 3$ and $\mathrm{C} 1$ have a strong relationship with rutting. However, between these two the parameter $\mathrm{C} 1$ strongly influences rutting than the parameter $\mathrm{C} 3$ [8].

\section{Asphalt viscoelastic behaviour}

The hot-mix asphalt materials plays a major role in asphalt pavement rutting. Most paving materials are not elastic, but if the load is small compared to the strength of the material and is repeated for a large number of times, the deformation under each load repetition is nearly completely recoverable and can be considered elastic $[13,14]$. The recoverable (elastic and viscoelastic) and nonrecoverable (plastic and viscoplastic) strains components are determined in the analyses. The viscoplastic strain component is the major contributor to the asphalt mixture rutting and only this component is used in the development of the material creep parameters [8]. If the creep model is used to describe the time dependant material behaviour, the repeated loading and continuous loading have the same effect on the predicted creep strain as long as the total loading times are the same.

\section{Hamburg wheel rut tester}

The Hamburg Wheel Tracking Device (HWTD) is well known in Canada as the Hamburg Wheel Rut Tester (HWRT). Ludomir Uzarowski 2006 employed The HWRT for asphalt mix accelerated performance testing in terms of its rutting resistance. The wheels can be either steel (47 mm wide) or solid rubber (50 mm wide), and the load applied to the wheels is $(710 \mathrm{~N})$. The customary temperature for the HWRT test in Canada and the United States is $50^{\circ} \mathrm{C}$; this temperature is also typically used in Europe for a climate close to a Superpave high temperature PG of 58 . The test path is $(230 \mathrm{~mm})$ long and the average speed of each wheel is approximately $1.1 \mathrm{~km} / \mathrm{h}(53 \pm 2$ wheel passes per minute). All the HWRT testing was carried out at a temperature of $50^{\circ} \mathrm{C}$. Fig. 1, shows the diagram of the Rutting Resistance Testing in the HWRT. 


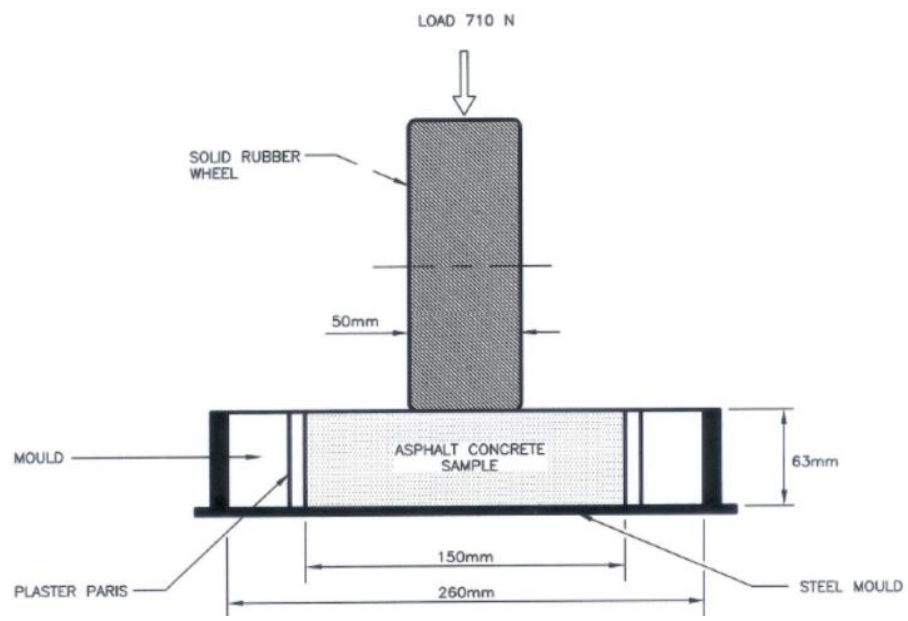

Fig. 1. Diagram of the Rutting Resistance Testing in the HWRT

Five asphalt mixes were used in this study [12]. These mixes present a wide range of applications, from high traffic to low volume roads. All five mixes were obtained from paving projects in Ontario [8]. In total, about one ton of asphalt mixes was used in the research and the designs for all five mixes were provided by the contractors who supplied the mixes. The mixes incorporated the aggregate types and asphalt cements listed in Table 1.

Table 1. Asphalt Mix Ingredients (12).

\begin{tabular}{|c|c|c|c|c|}
\hline \multirow{2}{*}{ Mix } & \multicolumn{2}{|c|}{ Aggregate } & \multirow{2}{*}{ Additives } & $\begin{array}{c}\text { Asphalt } \\
\text { Cement Grade }\end{array}$ \\
\cline { 2 - 3 } HL 3 & $\begin{array}{c}\text { Crushed } \\
\text { gravel (40\%) }\end{array}$ & $\begin{array}{c}\text { Asphalt sand (45\%) and } \\
\text { screening (15\%) }\end{array}$ & - & PG 58-28 \\
\hline SMA L & $\begin{array}{c}\text { Traprock } \\
(79 \%)\end{array}$ & $\begin{array}{c}\text { Traprock (13\%) and } \\
\text { mineral filler (8\%) }\end{array}$ & $\begin{array}{c}\text { Cellulose fibre } \\
(0.3 \%)\end{array}$ & PG 70-28 PM* \\
\hline SMAG & Traprock & $\begin{array}{c}\text { Traprock and mineral } \\
\text { filler }\end{array}$ & $\begin{array}{c}\text { Cellulose fibre } \\
(0.3 \%)\end{array}$ & PG 70-28 PM* \\
\hline SP 19 D & $\begin{array}{c}\text { Crushed rock } \\
(39 \%)\end{array}$ & $\begin{array}{c}\text { Screenings (10\%) } \\
\text { and manufactured sand } \\
(51 \%)\end{array}$ & - & PG 64-28 \\
\hline SP 19 E & $\begin{array}{c}\text { Crushed rock } \\
(63 \%)\end{array}$ & $\begin{array}{c}\text { High stability sand } \\
(37 \%)\end{array}$ & - & PG 70-28 \\
\hline
\end{tabular}

\section{Creep model parameters}

Five material parameters may affect the rutting predicted by the finite element method. These parameters include three creep model parameters (C1, C2 and C3) and two elastic parameters (modulus of elasticity, and Poison's ratio). However, predicted rut depth is not sensitive to modulus of elasticity and Poison's ratio since these two factors only define the elastic behaviour, which is not directly related to the permanent deformation. Therefore, the sensitivity study was kept limited to the creep model parameters [9]. In this analysis, the modulus of elasticity obtained from the triaxial repeated load creep test based on Uzarowski, L. [11] work has been used. The triaxial repeated load creep test done at a 
temperature of $50^{\circ} \mathrm{C}$ and at a frequency of $1 \mathrm{~Hz}$. The Poisson's ratio is calculated using the Eq. 1. given in MEPDG [8]:

$$
\mu_{a c}=0.15+\frac{0.35}{1+e^{-1.63+\left(3.84 * 10^{-6}\right) E_{a c}}}
$$

Where:

$\mu_{a c}=$ Poisson's ratio of asphalt mix at a specific temperature

$E_{a c}=$ modulus of asphalt mix at a specific temperature (psi)

The creep parameters $C 1, C 2$ and $C 3$ have been calibrated based on the rutting measured in the HWRT. The $C 3$ parameter is stress related. The rut resistance testing in the HWRT is conducted at a constant loading stress of $500 \mathrm{kPa}$, the $C 3$ parameter is fixed at the initial level shown in Table 2. Parameter $C 1$ is the value of the y-axis intercept while parameter $C 2$ is related to the slope of the strain-time relationship curve in a log-log scale [4]. The elastic and final creep parameters used in the simulation are shown in Table 2.

Table 2. Asphalt mix elastic and creep parameters.

\begin{tabular}{|c|c|c|c|c|c|}
\hline & \multicolumn{5}{|c|}{ Material Parameter } \\
\hline & \multicolumn{2}{|c|}{ Elastic } & \multicolumn{3}{c|}{ Creep } \\
\hline Mix Type & $\begin{array}{c}\text { Modulus } \\
\text { kPa }\end{array}$ & $\begin{array}{c}\text { Poisson's } \\
\text { Ratio }\end{array}$ & $\begin{array}{c}\boldsymbol{C 1} \\
(\mathbf{x 1 0 - 8})\end{array}$ & $\boldsymbol{C 2}$ & $\boldsymbol{C 3}$ \\
\hline HL3 & 950,000 & 0.41 & 41 & 1.48 & -0.63 \\
\hline SMAL & 800,000 & 0.42 & 509 & 1.04 & -0.78 \\
\hline SMA G & 800,000 & 0.42 & 138 & 1.31 & -0.79 \\
\hline SP 19 D & $1,600,000$ & 0.39 & 66 & 1.20 & -0.68 \\
\hline SP19 E & $1,400,000$ & 0.40 & 72 & 1.20 & -0.64 \\
\hline
\end{tabular}

\section{ANSYS modelling}

ANSYS is a suite of powerful engineering simulation based on the finite element method. It has an extensive library of finite elements and an extensive list of material models. Analysis in ANSYS includes two stages starting level and processing level, starting level include converting a mechanical problem for finite element model (FEM). Processing level includes three steps Pre-processing, Solve and Post-processing. The geometry of problem, material properties, element type and boundary conditions has been defined in Preprocessing step. While in the solve step, the type of analysis has been chosen. Finally the result of solving the problem has been observed in the Post-processing step (ANSYS user's manual-version 9.0 2004). There are lots of equations embedded in commercial finite element analysis software (ANSYS). In order to model primary and secondary stages of creep characteristics, the presented creep model used in this research can be written in the form of creep strain rate. The material is assumed to be isotropic and the basic solution technique used is the initial-stiffness Newton-Raphson method as in Eq. 2.

$$
\dot{\varepsilon}_{c r}=C_{1} \sigma^{c_{2}} t^{c_{3}}
$$

where $\dot{\varepsilon}_{c r}$ is the creep strain rate, $r$ is the equivalent stress, $t$ is the time at the end of sub-steps, $C 1, C 2$ and $C 3$ are the parameters related to material properties. As the temperature in the analysis is fixed at $50^{\circ} C$, the parameters $C 1, C 2$ and $C 3$ are developed from the triaxial repeated load creep test at $50^{\circ} \mathrm{C}$ and the modulus of elasticity and Poisson's ratio determined at the same temperature. The elastic parameters modulus of elasticity and Poisson's ratio and creep parameters $C 1, C 2$ and $C 3$ are required for the 
finite element simulator (ANSYS) in order to calculate the rutting for various mixes under a uniform loading pressure of $500 \mathrm{kPa}$.

\section{Finite element simulation}

The structure and the auxiliary conditions in the finite element simulation have to be correctly modelled to obtain reasonable results. This includes the finfite element model's components such as include element type, boundary conditions, load conditions, material properties and geometry of the model As shown in Fig. 2, $150 \mathrm{~mm} \times 300 \mathrm{~mm}$ (in width) and $63 \mathrm{~mm}$ (in height) rectangular bituminous mixture structure was constructed to simulate the Hamburg Wheel Rut Test.

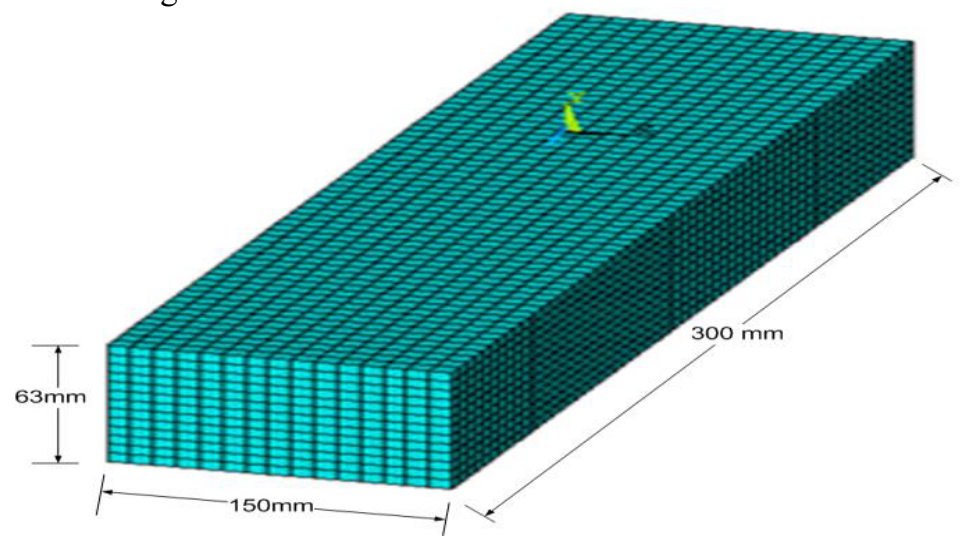

Fig. 2. Finite element mesh of wheel tracking test specimen.

The dual wheel loading configurations in the HWRT testing are symmetrical as shown in Figure 3, to reduce the element number and the required time for each analysis, only one wheel and half of the HWRT sample was included in the finite element modelling. The load magnitude was $710 \mathrm{~N}$ with $500 \mathrm{kpa}$ tire pressure. The material creeps model discussed above was used to characterize the permanent deformation properties of the bituminous mixture. The parameters used in the creep model were derived from the triaxial repeated load creep test result. The bottom and the four surrounding vertical boundaries were set to be confined with restricting displacement in all directions except the axisymmetric side which is surrounding is an $\mathrm{x}$ direction only. SOLID45 is used for the 3-D modelling of solid structures and this element is defined by eight nodes having three degrees of freedom at each node translation in the nodal $\mathrm{x}, \mathrm{y}$, and $\mathrm{z}$ directions. The element has plasticity, creep, swelling, stress stiffening, large deflection, and large strain capabilities. 


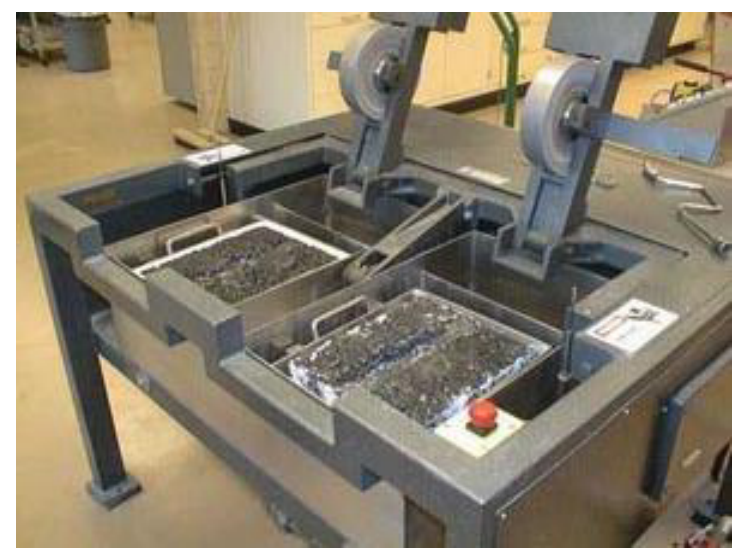

Fig. 3. General view of the Hamburg Wheel Rut Tester.

\section{Result and discussion}

The measured rut depth versus time relationship with rutting predicted in ANSYS and ABAQUS at the time of loading of about 1000, 1800, 2600, 3300 and $4200 \mathrm{sec}$ has been shown in the Figures 4,5,6,7 and 8. The results show that there is a reasonable agreement on the difference between the predicted rutting values and the laboratory measured rutting values. The comparison between the obtained results from ABAQUS and the results obtained from ANSYS shows that rutting values from ANSYS are closer to the laboratory measured values.

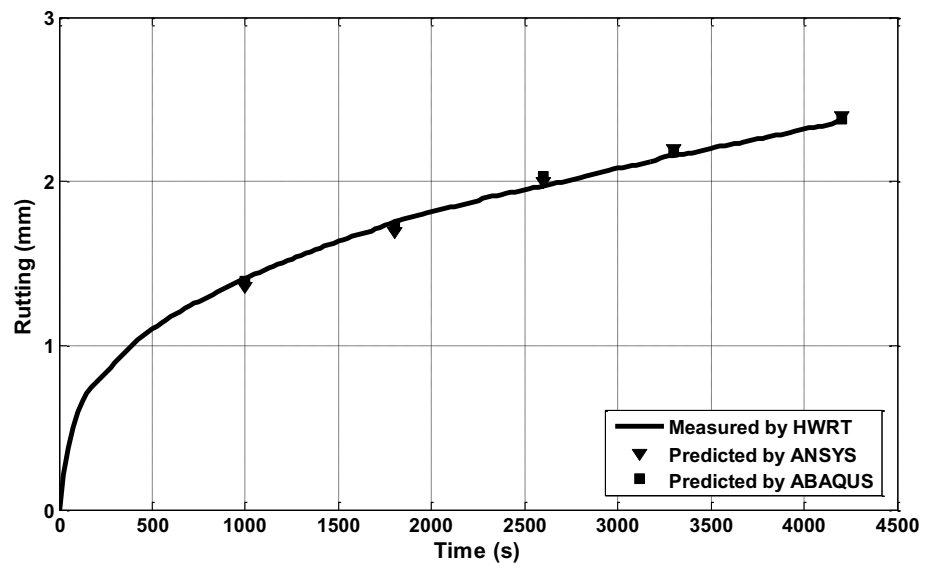

Fig. 4. Rutting measured in HWRT and predicted in ABAQUS and ANSYS for the HL 3 Mix. 


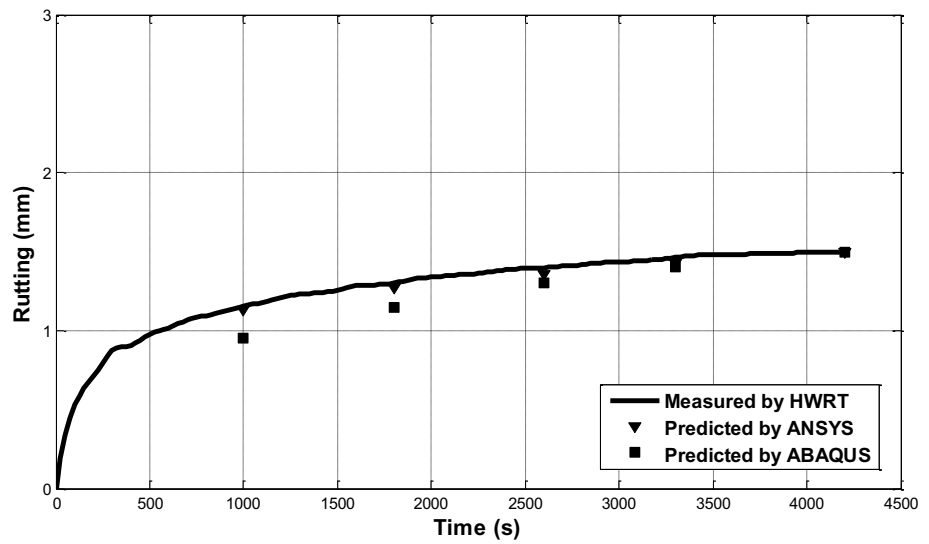

Fig. 5. Rutting measured in HWRT and predicted in ABAQUS and ANSYS for the SMA L Mix.

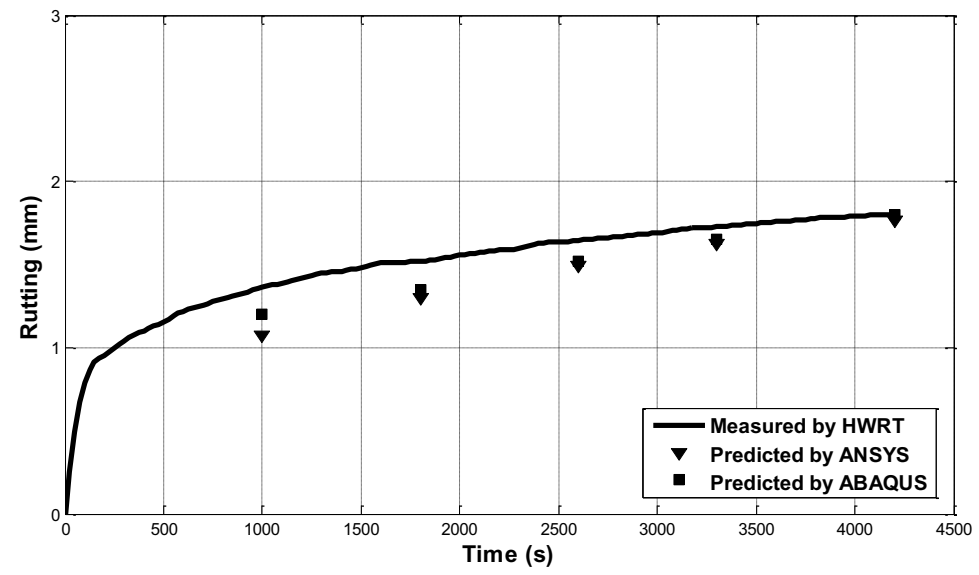

Fig. 6. Rutting measured in HWRT and predicted in ABAQUS and ANSYS for the SMA G Mix.

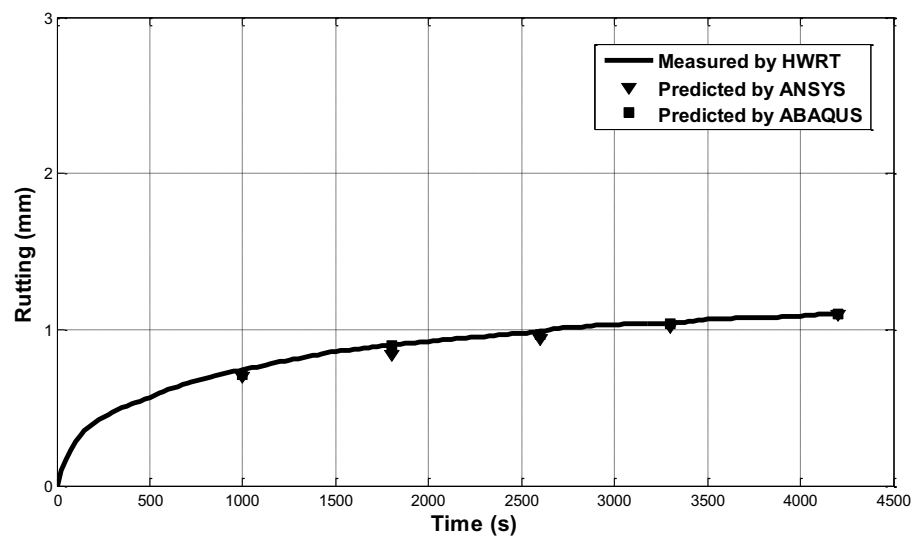

Fig. 7. Rutting measured in HWRT and predicted in ABAQUS and ANSYS for the SP 19 D Mix. 


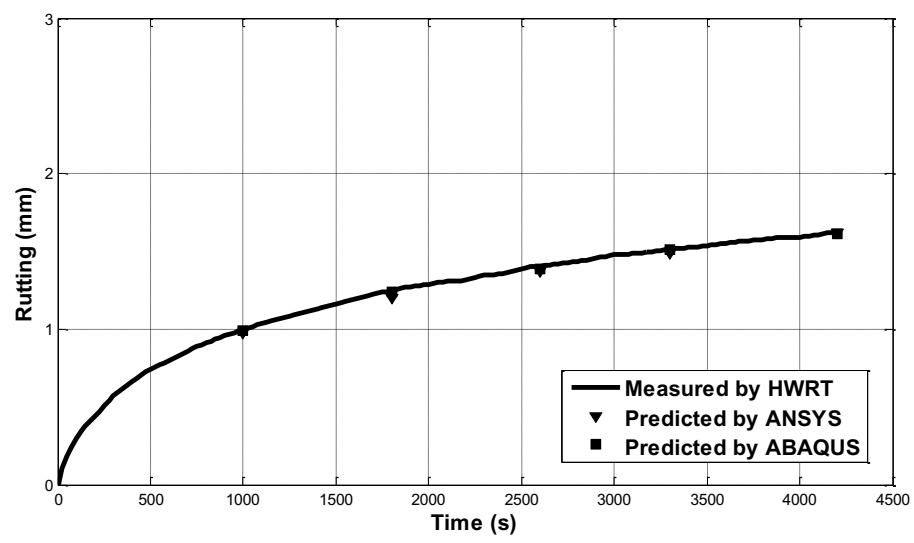

Fig. 8. Rutting measured in HWRT and predicted in ABAQUS and ANSYS for the SP 19 E Mix.

There are a total of five possible factors, which may affect the predicted model response. They are creeping model parameters $C 1, C 2$ and $C 3$, modulus of elasticity and Poisson's Ratio. The result of this work simulation shows that the predicted rut depth is not sensitive to modulus of elasticity and Poisson's Ratio. This expected since these two factors only define the elastic behaviour which is not directly related to permanent deformation. It was clear that the parameter $C 1$ strongly influences rutting than the parameter $C 3$ As can be seen from Fig. 9, predicted rut depth increases with increasing $C 1$ value. As can be seen from Figure 10, predicted rut depth increases with increasing $C 3$ value (noted that $C 3$ is in the range from -1 to 0 ) The relationship of $C 3$ and the predicted rut depth is non-linear as shown in fig. 10 .

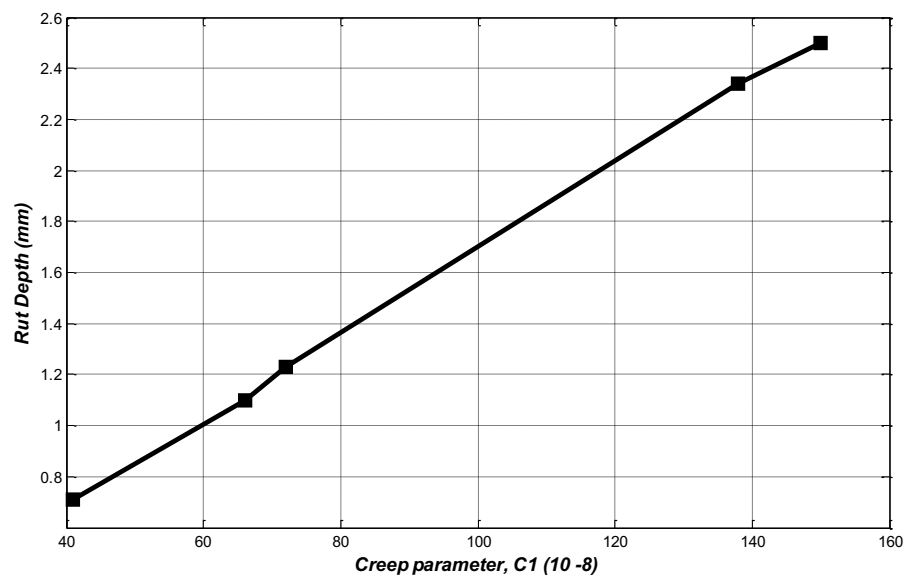

Fig. 9. The effect of varying Creep Model Parameter $C l$ on Rut Depth. 


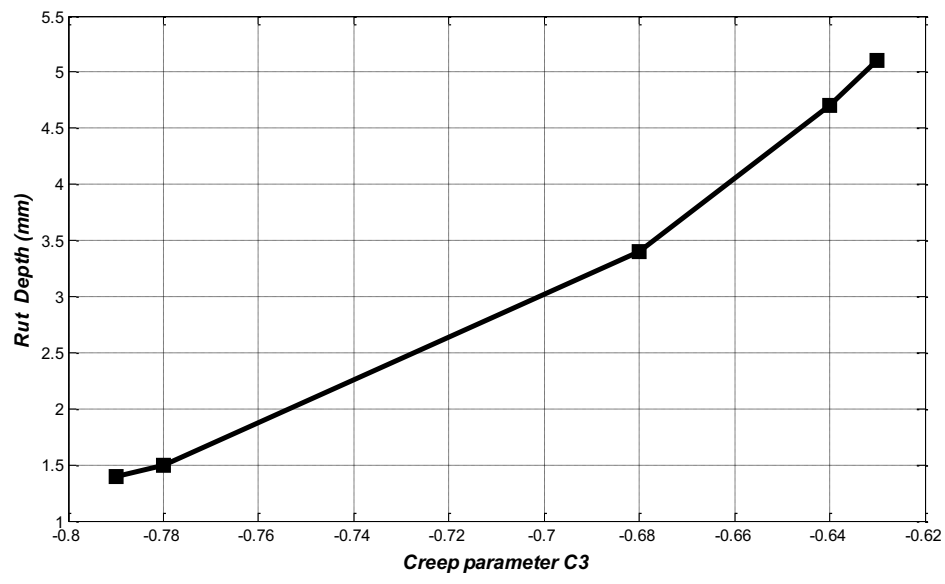

Fig. 10. The effect of varying Creep Model Parameter $C 3$ on Rut Depth.

\section{Conclusion}

The finite element model developed for HWRT tester was verified by comparing predicted and measured rut depths and also by comparing the rut depth with ABAQUS result from literature. Reasonable agreement was found between the predicted and measured rut depths furthermore, it was found that creep model parameters $C 1$ and $C 3$ have a strong relationship with rutting and that the parameter $C 1$ strongly influences rutting than the parameter $C 3$. It was clear that the predicted rut depth increases with increasing $C 1$ value and with increasing $C 3$ value. The parameters $C 1$ and $C 3$ are closely related to the amount of asphalt content and the air void in hot mix asphalt. Finally, it can be concluded that creep model based on finite element method can be used as effective tools to analyse rutting of asphalt pavements.

\section{References}

1. M.E. Abukhettala, The relationship between marshall stability, flow and rutting of the New Malaysian hot-mix asphalt mixtures, (Universiti Teknologi Malaysia, Johor Bahru, 2006)

2. M.H. Nahi, A. Ismail, A.K. Anffm, J. Appl. Sci., 11, 2562 (2011)

3. B.A. Feyissa, Analysis and modeling of rutting for long life asphalt concrete pavement, (TU, Darmstadt, 2009)

4. U.S. Department of Transportation, Hamburg wheel tracking device, (Federal Highway Administration, Turner-Fairbank Highway Research Center, McLean, VA, 2002)

5. M.A.A. Zahw, Development of testing framework for evaluation of rutting resistance of asphalt mixes, (Faculty of Engineering, Al-Azhar University, 1996)

6. M.H. Nahi, I. Kamaruddin, A. Ismail, R.A.E. Al Mansob, J. Appl. Sci., 14, 2730 (2014)

7. NCHRP, Guide for mechanistic-empirical design of new and rehabilitated pavement structures. (National Cooperative Highway Research Program, Illinois, 2004) 
8. S. Pirabarooban, M. Zaman, R.A. Tarefder, Evaluation of Rutting Potential in Asphalt Mixes Using Finite Element Modeling, Annual Conference and Exhibition of the Transportation Association of Canada (2003)

9. M.H. Nahi, I. Kamaruddin, M. Napiah, Appl. Mech. Mater., 567 (2014)

10. Texas DOT. Pavement construction specifications. Texas Department of Transportation, (2003)

11. L. Uzarowski, The development of asphalt mix creep parameters and finite element modeling of asphalt rutting, (University of Waterloo, Canada, 2007)

12. D. Walker, M. Buncher, Intersection Strategy, (Asphalt Institute, Kentucky, 1999)

13. D.Walker, M. Buncher, A. Institute, High performance hot mix asphalt intersection strategy (Asphalt Institute, Kentucky, 2004) 